\title{
Listeriose em rebanho de ovinos leiteiros na região serrana do Rio Grande do Sul: relato de caso
}

[Listeriosis in a dairy sheep herd in Rio Grande do Sul state, Brazil: case report]

\author{
L.A.O. Ribeiro ${ }^{1}$, N.C. Rodrigues ${ }^{2}$, L.C.B. Fallavena ${ }^{2}$, S.J. Oliveira $^{2}$, M.A. Brito ${ }^{3}$ \\ ${ }^{1}$ Faculdade de Veterinária - UFRGS \\ Av. Bento Gonçalves, 9090 \\ 91540-000 - Porto Alegre, RS \\ ${ }^{2}$ Faculdade de Veterinária - ULBRA - Canoas, RS \\ ${ }^{3}$ Aluno de pós-graduação - EV-UFRGS
}

\begin{abstract}
RESUMO
Relatam-se dois casos de listeriose ocorridos em ovinos leiteiros da raça Lacaune, mantidos em confinamento e alimentados com silagem de milho. $\mathrm{O}$ exame histológico do tecido nervoso mostrou meningoencefalite supurada, e a imunoistoquímica foi positiva para Listeria monocytogenes com isolamento da bactéria do tecido nervoso. Enfatiza-se a ocorrência dessa enfermidade em ovinos leiteiros que apresentavam lesões na cavidade oral e eram alimentados com silagem de baixa qualidade.
\end{abstract}

Palavras-chave: ovino, Listeria monocytogenes, listeriose

\section{ABSTRACT}

Clinical cases of listeriosis in two Lacaune rams, fed silage in a lot, are reported. Histological examination of nervous tissue revealed purulent meningoencephalitis, and L. monocytogenes was detected in nervous tissue by immunohistochemistry procedures. This disease should be suspected when oral lesions are visible in dairy sheep fed low quality silage.

Keywords: sheep, Listeria monocytogenes, listeriosis, silage

\section{INTRODUÇÃO}

A listeriose em ovinos, em uma de suas formas clínicas, causa encefalite, sendo a silagem mal conservada, com $\mathrm{pH}$ acima de 5,5, a principal fonte do agente Listeria monocytogenes (Clarkson e Winter, 1997). No Brasil, a doença em ovinos é rara, tendo sido relatada, inicialmente, por Fernandes et al. (1971), no Rio Grande do Sul (RS), e mais recentemente por Basile et al. (1992), no Paraná, e Consorte (1994), no Rio de Janeiro. Os casos descritos no RS e no Paraná referem-se à forma nervosa da doença, ocorridos no final do inverno e início da primavera, sem divulgação dos detalhes sobre o regime alimentar ao qual os ovinos estavam submetidos.

O objetivo deste trabalho é relatar dois casos de listeriose ocorridos em um rebanho ovino leiteiro da região serrana do $\mathrm{RS}$.

\section{CASUÍSTICA}

Em um rebanho de ovinos leiteiros da raça Lacaune, alimentados com silagem de milho, observaram-se dois carneiros, com idades entre

Recebido em 23 de agosto de 2004

Aceito em 13 de junho de 2005

E-mail: berto@ufrgs.br 
um e dois anos, com sintomatologia nervosa. O manejo sanitário envolvia vacinação anual contra clostridiose e tratamentos anti-helmínticos periódicos.

Os animais, examinados clinicamente, após o óbito, foram necropsiados, para colheita de amostras do cérebro, fígado e rins para exame histológico. Após fixação em formalina a $10 \%$, as amostras foram incluídas em parafina, seccionadas a $5 \mu \mathrm{m}$ e coradas pela técnica da hematoxilina e eosina (Luna, 1968). As preparações para o método de imunoistoquímica (IHQ) seguiram a técnica descrita por Schwab (2003), utilizando tecido nervoso incluído em parafina.

Um fragmento do cérebro foi coletado e mantido em refrigeração para exame bacteriológico. A técnica bacteriológica utilizada foi a descrita por Oliveira (2000).

\section{RESULTADOS E DISCUSSÃO}

Os animais, inicialmente, mostraram apatia e anorexia e, em um deles, observou-se aumento de temperatura retal $\left(40^{\circ} \mathrm{C}\right) . \mathrm{O}$ exame da cavidade oral revelou lesões na gengiva, provavelmente causadas por mudança na dentição. $\mathrm{O}$ aparecimento dos sintomas foi lento, com aparente recuperação após aplicação de dose única de cloridrato de oxitetraciclina na dose de $0,02 \mathrm{~g} / \mathrm{kg}$. Entretanto, houve recidiva da doença, com picos febris e evolução final para dificuldade locomotora. Após quatro semanas, os animais apresentavam-se em decúbito esternal e com crises convulsivas.

Não foram observadas lesões macroscópicas dignas de nota. $O$ fígado não apresentou alterações significativas, nos rins observou-se inflamação intersticial focal, e o encéfalo exibiu meningoencefalite purulenta (Fig. 1). O exame de IHQ foi positivo para L. monocytogenes (Fig. 2).
A cultura do tecido cerebral em ágar-sangue revelou colônias hemolíticas, aeróbicas, catalase e oxidase negativas. O organismo fermentou glicose, maltose e indol, sendo negativo para gás sulfídrico. A bacterioscopia revelou bastonetes pequenos Gram-positivos, cujas características colonial, bioquímica e morfológica foram típicas de L. monocytogenes.

O diagnóstico de meningoencefalite por listeriose baseou-se na histopatologia, pelo isolamento de um organismo com características de L. monocytogenes e no exame histoquímico positivo para essa bactéria.

Os casos relatados neste estudo assumem importância significativa por ocorrerem em ovelhas produtoras de leite, que estão submetidas a manejo alimentar diferenciado dos sistemas de criação utilizados para a espécie no RS. Cabe salientar que a provável fonte de entrada do agente foram as lesões orais causadas pela muda dentária. Low e Linklater (1991) afirmaram que casos naturais de encefalite por Listeria em ovinos é resultado de solução de continuidade na mucosa oral, que favorece a penetração do agente. Este, por meio do nervo trigeminal, alcança o cérebro. $\mathrm{O}$ fato de os animais serem criados em confinamento aumentaria o risco de contaminação, conforme sugerido por Green e Morgan (1994).

A ingestão de silagem de milho pelos ovinos seria a principal fonte de $L$ monocytogenes. Embora não se tenha medido o $\mathrm{pH}$ da silagem e não tenha sido feito exame bacteriológico, a sua qualidade foi considerada pobre, a julgar-se pelas alterações observadas quanto ao aspecto e odor.

Apesar de já registrada em ovinos no Brasil, a ocorrência da listeriose é esporádica. Por tratarse de uma zoonose, são importantes a rapidez de diagnóstico e a adoção de medidas preventivas. Nesse caso específico, assume relevância para a saúde pública o fato de tratar-se de um rebanho ovino, cujo leite é empregado na produção de queijos e iogurtes, que são comercializados. 


\section{Ribeiro et al.}

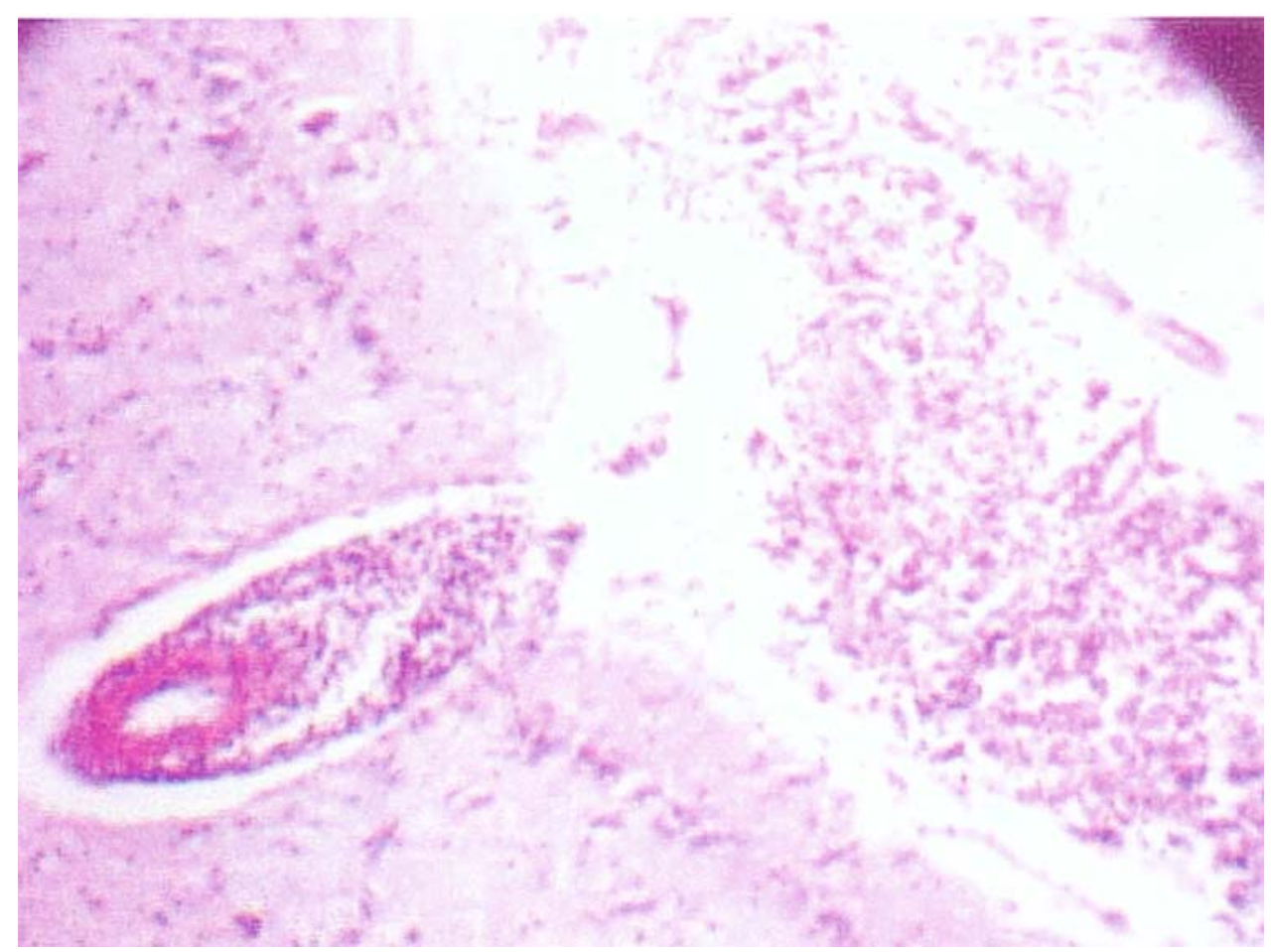

Figura 1. Encéfalo de ovino.Meningoencefalite purulenta. Hematoxilina-eosina.100×.

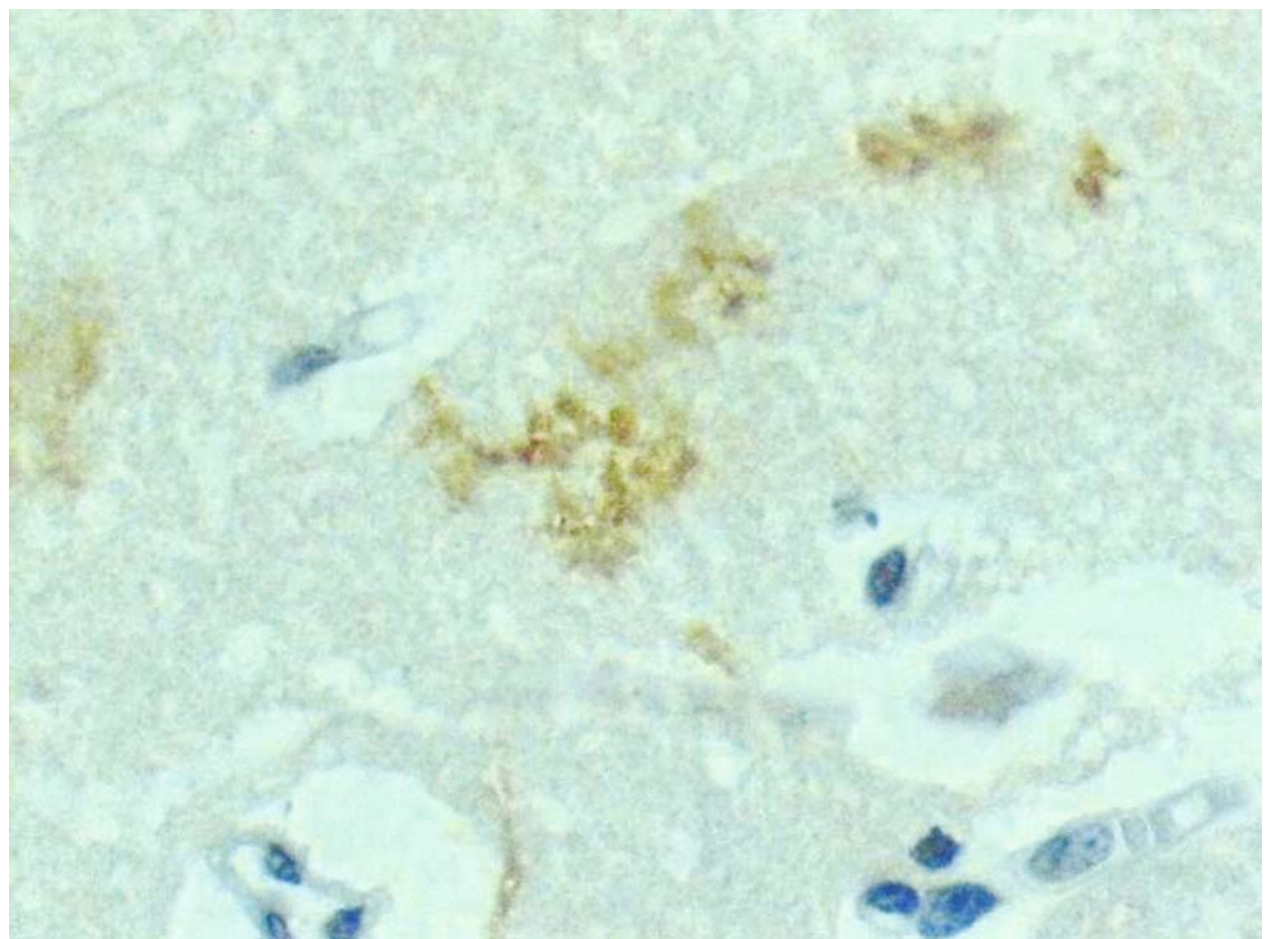

Figura 2. Encéfalo de ovino. AcMo anti-Listeria, hematoxilina de Mayer.400×. 


\section{REFERÊNCIAS BIBLIOGRÁFICAS}

BASILE, J.R.; SOARES, L.R.; HEIM, C. et al. Listeriose em ovinos no Estado do Paraná. In: CONGRESSO BRASILEIRO DE MEDICINA VETERINÁRIA, 22., 1992, Curitiba. Anais... Curitiba, 1992. p.394. (Resumo).

CLARKSON, M.J.; WINTER, A.C. (Ed.). A handbook for the sheep clinician. 4.ed. Liverpool: Liverpoll University, 1997. 185p.

CONSORTE, L.B.S. Diagnóstico sorológico da listeriose caprina no Rio de Janeiro. 1994. $143 \mathrm{f}$. Dissertação (Mestrado em Microbiologia Veterinária) - Faculdade de Veterinária, Universidade Federal Rural do Rio de Janeiro, Seropédica, RJ.

FERNADES, J.C.T.; BOLLWANN, W.; SIQUEIRA, C.S. Listeriose em ovinos no Rio Grande do Sul: descrição de um caso. Rev. Med. Vet., v.7, p.131-137, 1971.

GREEN, L.E.; MORGAN, K.L. Descriptive epidemiology of Listeria meningoencephalitis in housed lambs. Prev. Vet. Med., v.18, p.79-87, 1994.

LOW, C.; LINKLATER, K. Listeriosis in sheep. In: BODEN, E. (Ed.). Sheep and goat practice. London: Baillière Tindall, 1991. cap. 12. p.113119.

LUNA, L.G. Manual of histologic staining methods of the Armed Forces Institute of Pathology. 13.ed. New York: McGraw-Hill, 1968. 258p.

OLIVEIRA, S.J. Microbiologia veterinária: guia bacteriológico prático. 2.ed. Canoas: ULBRA, 2000. 236p.

SCHWAB, J.P. Padronização da técnica de imunoistoquímica para identificação de Listeria monocytogenes em placentas humanas e tecido nervoso central de ruminantes. 2003. 76f. Tese (Doutorado em Ciências Veterinárias) Faculdade de Veterinária, Universidade Federal do Rio Grande do Sul, Porto Alegre. 